\title{
Re: Implications for the future of Obstetrics and Gynaecology following the COVID-19 pandemic: A commentary. (First comment on BJOG-20-1161.R1)
}

\author{
Jonathan Herron ${ }^{1}$ and Rachel Herron ${ }^{2}$ \\ ${ }^{1}$ University of Sunderland \\ ${ }^{2}$ Northumbria University
}

September 22, 2020

Dear Sir,

We read with interest Kasaven et al., (1) who eloquently describe some of the implications to the practice of obstetrics and gynaecology. They correctly identify the heightened anxiety that patient's face when attending hospital during pregnancy. During this time the reduction in patient attendance can be multifactorial. However, we feel one area which has been neglected is partner support. There is evidence that having a partner present during a birth can reduce a woman's anxiety and additionally be beneficial to the partner (2). Father's also can experience significant anxiety in the peri-natal period (2) and maternal stress particularly with relationship strain can be harmful to the baby. Parental presence during CPR for a child is beneficial for parents as they can make sense of the situation. It logically would also be beneficial to partners with maternal emergency caesarean sections and of course postnatally to bond with the baby (3). Current policy dictates that fathers can only be present during the birth, however in a multiparous woman or a woman requiring a crash caesarean section the timeframe allowing for partner's attendance is not reasonable or feasible. COVID-19 is clearly the reason for this policy, however, examining the risk of a couple, who have both been screened as negative on a COVID-19 test and live in the same household. If the male member of the couple has COVID-19 the female is likely to have a high viral load from the partner due to kissing or sexual intercourse (4), a common practice in an attempt to induce labour. The early knowledge of infection can allow for appropriate infection control measures to be put in place. The rate of a false negative is $4-30 \%$ (4) but this is still a risk with the mother. The risk to staff with correct personal protective equipment and training is minimal (4). Additionally, women who do not have continuous support are more likely to have an instrumental/surgical delivery, use more pain medication, prolonged labours which may result in complications such as postpartem haemorrhage (5), which ultimately places hospitals and clinicians at greater risk of litigation. With risk of domestic violence and risk of increased mental health issues as highlighted by Kasaven et al., are we doing more harm than good and is this an unintended consequence of COVID-19 that could be prevented? The implication to patient care is huge for what appears to be little benefit. Have we forgotten that we should be delivering patient centred care? Perhaps it is time for change.

Herron JBT (1), Herron RL (2)

1. University of Sunderland, Faculty of health science and wellbeing, Chester Road, Sunderland SR1 3SD.

2. Northumbria University, School of Nursing, Midwifery and Health, 2 Sandyford Rd, Newcastle upon Tyne NE1 8QH.

\section{References}

1. Kasaven LS, Saso S, Barcroft J, Yazbek J, Joash K, Stalder C, et al. Implications for the future of 
Obstetrics and Gynaecology following the COVID-19 pandemic: a commentary. BJOG: An International Journal of Obstetrics and Gynaecology. 2020 Jul 27; 127(11):1318-1323.

2. Chan KKL, Paterson-Brown S. How do fathers feel after accompanying their partners in labour and delivery? J Obstet Gynaecol (Lahore). 2009 Jul 2; 22(1):11-15.

3. Pfannenstiel AE, Honig AS. Effects of a prenatal "Information and Insights about Infants" program on the knowledge base of first-time low-education fathers one month postnatally. Early Child Dev Care. 1995 July; 111:87-105.

4. Herron JBT, Hay-David AGC, Gilliam AD, Brennan PA. Personal protective equipment and Covid 19- a risk to healthcare staff? British Journal of Oral and Maxillofacial Surgery. 2020 Jun; 58(5):500-502.

5. Bohren MA, Hofmeyr GJ, Sakala C, Fukuzawa RK, Cuthbert A. Continuous support for women during childbirth. Cochrane Database of Systematic Reviews. 2017 Jul 6; 7:CD003766. 